Eur. J. Clin. Chem. Clin. Biochem.

Vol. 32, 1994, pp. 789-796

(C) 1994 Walter de Gruyter \& Co. Berlin - New York

\title{
Generation of Reference Values for Cardiac Enzymes from Hospital Admission Laboratory Data
}

\author{
By Veli Kairisto ${ }^{1,4}$, Kai-Petri Hänninen ${ }^{2}$, Aila Leino ${ }^{3}$,Kari Pulkki ${ }^{4}$, Olli Peltola ${ }^{4}$, Veikko Näntö ${ }^{1.4}$, Liisa-Maria \\ Voipio-Pulkki ${ }^{2}$ and Kerttu Irjala ${ }^{4}$ \\ 1 Department of Clinical Chemistry, University of Turku, Finland \\ 2 Department of Medicine, University Central Hospital of Turku, Finland \\ ${ }^{3}$ Rehabilitation Research Centre in Turku, Finnish Social Insurance Institution \\ ${ }^{4}$ Central Laboratory, University Central Hospital of Turku, Finland
}

(Received February 16/July 14, 1994)

Summary: An approach is described for using patient databases of a hospital information system as a source of reference values for cardiac enzymes. Of a total of 2029 emergency admission patients with serial cardiac enzyme data, 538 patients were considered "healthy" (having no damage in myocardium) because their discharge diagnoses suggested neither myocardial damage nor any other condition that could lead to elevated enzyme activities, and because their serially collected cardiac enzyme activities remained stable. Enzyme activities of creatine kinase (EC 2.7.3.2), creatine kinase isoenzyme $\mathrm{MB}$, lactate dehydrogenase (EC 1.1.1.28), and lactate dehydrogenase isoenzyme 1 of these patients at admission to hospital were considered as suitable health related reference values. The upper (97.5\%) reference limits of activities, measured at $37^{\circ} \mathrm{C}$ according to Scandinavian recommendations, were as follows (age dependent limits given at 25 and at 75 years of age, U/l): creatine kinase men 268, 192; creatine kinase women 200 (no age effect); creatine kinase-MB 16, 24; lactate dehydrogenase 497, 603; lactate dehydrogenase isoenzyme 1103,140 . For comparison, reference values were also produced conventionally from a group of 246 healthy subjects. Observed effects of age on enzyme activities were quite similar to those in the selected patient group. Calculated reference limits for isoenzymes creatine kinase-MB and lactate dehydrogenase isoenzyme 1 were also similar but reference limits for less cardiospecific total enzyme activities, creatine kinase and lactate dehydrogenase, were more variable between these two groups. Observed differences in total enzyme activity levels may reflect different preanalytical conditions of emergency admission patients and conventional reference subjects, in which case reference values produced from selected "healthy" emergency admission patients would be more suitable for clinical use. We conclude that reference values can be produced from patient databases with relatively little effort and at low cost provided that the database information is clinically adequate and reliable.

\section{Introduction}

Production of reference values is an essential function of a clinical laboratory. Usually reference values are produced by prospective data samplings of individuals representing the healthy population. For good clinical applicability it is important that the reference individuals are as comparable to the patients as possible, except for the considered disease (1). The value of standardizing preanalytical conditions when producing reference values can be questioned if similar standards cannot be ap- plied in the production of actual clinical laboratory data. Therefore characteristics of the patient population, like age distribution and most typical preanalytical conditions, should be investigated before producing reference values. The reference population should be selected according to these characteristics.

Computerised laboratories store large amounts of data of laboratory test results. In principle it would be possible to produce both health- and sickness-related reference values from these databases, if there were enough 
reliable information for classifying the data in different diagnostic categories. Information of laboratory test results and sample collection times are usually readily available in the laboratory databases. Another available database in many hospitals is the discharge diagnosis database, which contains hospital admission and discharge dates, discharge diagnoses and codes of possible operative therapy. Combination of data from these two databases is technically possible. It is also possible to do it without violating patient data security as all personal identification data can be removed during the combination process. We studied the possibilities of using combined database information as a source of reference values for myocardial enzymes. In addition to laboratory data, clinical discharge diagnoses were available for the retrospective selection of reference subjects.

Ideally, reference subjects should be as similar to the patients as possible, except for the disease. For laboratory diagnosis of myocardial infarction, the first blood samples are usually collected at the emergency department soon after patient's admission. Emergency admission patients are emotionally stressed, may have eaten or may have been physically active just prior to admission. The time of emergency sample collection is not standardized with respect to possible diurnal rhythms. Changes in the above mentioned conditions are known to affect the serum levels of creatine kinase ${ }^{1}$ ) and lactate dehydrogenase $\left.{ }^{1}\right)(2-5)$. To meet the demand of similarity of preanalytical conditions between patients and reference subjects, it can be argued that patients hospitalised with chest pain but later proved not to have suffered from myocardial infarction would be ideal reference subjects. Selection of such patients should be possible, as according to several reports only about $20-$ $30 \%$ of all patients suspected of myocardial infarction at admission to hospital are diagnosed as such by the time they are discharged (6-9).

Several aspects must be considered when selecting reference subjects a posteriori. The registered patient discharge diagnoses stored in patient databases may not be completely relevant or reliable enough for the selection of reference subjects $(10-13)$. The fact that also non-myocardial infarction patients with unstable angina may have microinfarcts and marginal elevations in cardiac markers $(14,15)$ is another difficulty in the utilisation of discharge diagnoses for the selection of healthy reference subjects. We believed that additional criteria not dependent on the patient diagnoses were needed. As a practical way of overcoming possible inadequacies in the discharge diag-

\footnotetext{
1) Enzymes:

Creatine kinase (EC 2.7.3.2), Creatine kinase isoenzyme MB; Lactate dehydrogenase (EC 1.1.1.28), Lactate dehydrogenase isoenzyme 1
}

nosis database, we took advantage of the available data of serially collected cardiac enzymes. Follow-up of myocardial markers is known to be among the most sensitive routinely available means of detecting myocardial damage $(16,17)$. Thus, we used changes between serial enzyme measurements as an additional selection criteria for defining the patient group with no myocardial damage. The limits for an acceptable change were obtained from our previously published data of patients who had no cardiac symptoms but who were hospitalised under conditions comparable to those of patients with chest pain (18). For comparison we also produced reference values from a group of healthy individuals.

\section{Materials and Methods}

Healthy reference subjects $(n=246)$

For the production of health related reference values, blood samples were collected from a group of 256 people. Informed consent was obtained from the individuals in accordance with the ethical standards of the Rehabilitation Research Centre of the Social Insurance Institution in Turku and the University Hospital of Turku. Reference subjects, who had not used any drugs during the preceding week, were included evenly from ages 27 to 67 years. They were advised to avoid any physical exertion and cigarette smoking during the preceding night and any alcohol consumption during the preceding day. Specimens were collected between 8 and 10 after an overnight fast, after the subject had been in a sitting position during the preceding 15 minutes. Ten subjects were excluded from the reference group for the following reasons: two for being trained athletes, five for muscular spasms, one for a recent operation, and two for macromolecular creatine kinase-BB forms. Of the remaining 246 healthy subjects 128 were men, ages 26 to 67 years (mean 46 years) and 118 women, ages 26 to 67 years (mean 47 years).

\section{Reference change limits}

The hospital admission related reference change limits were obtained from our previously published serial data of 29 non-cardiac patients (18). Fifteen of these patients were men, ages 36 to 77 years (mean 58) and 14 women, ages 18 to 73 years (mean 51 years). The homogeneity of within-subject variances was assured before using the two standard deviation limits of the distributions of changes as reference change limits. These limits were as follows: Creatine kinase $-42-22 \mathrm{U} / \mathrm{l}$, creatine kinase-MB -8 $-8 U / 1$, lactate dehydrogenase $-107-91 U / 1$ and lactate dehydrogenase isoenzyme $1-19-12 \mathrm{U} / \mathrm{l}(18)$.

\section{Patients}

For the retrospective evaluation we included 2029 consecutive emergency admission patients with an initial suspicion of myo= cardial infarction or myocarditis and with at least two creatine kinase determinations on the same or on two consecutive days. The same patient group was presented in our previous publication of a method for the calculation of reference change limits (18). Of the patients 1192 were men, ages 18 to 92 years (mean 63 years), and 837 were women, ages 26 to 98 years (mean 71 years). The first specimen for cardiac enzyme measurements was collected at admission to hospital. Serum total creatine kiñase and total lactate dehydrogenase activities were measured in this sample. The activities of heart specific isoenzymes (creatine . kinase-MB and lactate dehydrogenase isoenzyme 1) were also measured, if so requested by the attending physician. At least the creatine kinase activity measurement was repeated for each 
patient approximately 14 hours after admission, and, according to clinical judgement, measurements of other enzymes were repeated as well. For the calculation of within-subject changes between successive measurements, we included the maximum of three serial samples from the maximum of three consecutive days.

\section{Selection of "healthy" reference patients $(\mathrm{n}=538)$}

In the reference group of "healthy" patients we only accepted patients who did not have any "exclusion diagnoses" when they were discharged from the hospital. Our list of "exclusion diagnoses" included all diseases that may have an effect on creatine kinase or lactate dehydrogenase activities according to citations by Friedman and Young in "Effects of Disease on Clinical Laboratory Tests", Washington, AACC Press (1989) (19). Selection of reference patients according to discharge diagnoses has been previously suggested and used by Kouri et al. (20). An additional exclusion criterion was based on changes between serial cardiac enzyme measurements so that all patients with changes exceeding the reference change limits were excluded as well.

\section{Selection of patients with angina pectoris $(\mathrm{n}=571)$}

In the reference group of "angina" patients we included all patients with the discharge diagnosis of angina pectoris. The clinical diagnosis of angina pectoris in this hospital is based on the criteria of the World Health Organisation as defined for the MONICA-project (21). Patients having any other disease with possible effect on creatine kinase or lactate dehydrogenase values were excluded from this group. Angina patients were further subdivided into two groups: one with all enzyme changes within reference change limits ("angina(-)" patients) and another with at least one enzyme change outside reference change limits ("angina( $(+)$ " patients). A similar division of angina patients into two groups has been previously used by Boetker et al. (22).

\section{Selection of patients with myocardial infarction $(n=471)$}

In the reference group of "myocardial infarction" patients we included all patients with a discharge diagnosis of myocardial infarction but no other diagnosis possibly affecting creatine kinase or lactate dehydrogenase values. The routine diagnosis of myocardial infarction in this hospital is based on the presence of at least two of the three criteria defined by the World Health Organisation (23); these are characteristic chest pain, unequivocal signs of infarction in the electrocardiogram, and an observed elevated enzyme activity of serum creatine kinase or lactate dehydrogenase or their cardiospecific isoenzymes.

\section{Analytical methods}

\section{Creatine kinase assay}

Total creatine kinase activity was determined using a Hitachi 704 or 717 analyser (Hitachi Ltd., Tokyǒ, Jạpan) and the Scandinavian recommended assay (24) with reagents supplied by Merck (Diagnostica Merck, Inc., Darmstadt, Germany). The between run CV was $3.4 \%$ at $144 \mathrm{U} /$.

\section{Creatine kinase-MB assay}

Creatine kinase B activity was determined after immunoinhibition of the creatine kinase subunit $M$ activity and subsequent measurement of the remaining creatine kinase activity in a $\mathrm{Hi}$ tachi 704 or 717 analyser with reagents supplied by Merck. The results were multiplied by two in order to estimate the creatine kinase-MB activity. The between run $\mathrm{CV}$ was $14.8 \%$ at 8.0 $\mathrm{U} / \mathrm{l}$. Because this method does not eliminate creatine kinase-BB isoenzyme activity, an electrophoretic separation of creatine kinase isoenzymes was performed if macromolecular creatine kinase forms were clinically suspected and always if creatine kinase-MB activity was over $20 \%$ of total creatine kinase activity. Electrophoresis was done in a Corning 720 electrophoretic device with gel supplied by Corning (Specialgel ${ }^{\circledR}$, Corning Diagnostics Ltd., Halstead, Essex, England).

\section{Lactate dehydrogenase assay}

Total lactate dehydrogenase activity was determined using a $\mathrm{Hi}$ tachi 704 or 717 analyser and the Scandinavian-recommended assay (25) with reagents made in the laboratory. The between run $\mathrm{CV}$ was $2.2 \%$ at $460 \mathrm{U} / \mathrm{l}$

\section{Lactate dehydrogenase isoenzyme l assay}

Lactate dehydrogenase isoenzyme 1 activity was determined after immunoprecipitation of the other lactate dehydrogenase isoenzymes and subsequent measurement of the remaining lactate dehydrogenase activity in a Hitachi 704 or 717 analyser using the precipitating antibody supplied by Roche (Isomune-LD ${ }^{\circledR}$, Roche Diagnostic Systems, Inc., Nutley, NJ, USA). The other lactate dehydrogenase reagent was made in the laboratory as above. The between run $\mathrm{CV}$ was $5.2 \%$ at $103 \mathrm{U} / \mathrm{l}$.

The protocol to ensure comparable enzyme activity measurements on both Hitachi analysers used in our laboratory involves identical reagents, identical measurement conditions and identical internal quality control samples at two or three levels. All enzyme activities were calculated in accordance with the Scandinavian recommendations $(24,25)$ using the molar absorptivities of NADH, which were measured in a Hitachi 704 or 717 , using a glucose standard and the hexokinase reaction (Gluco-Quant Glucose, Boehringer Mannheim, Mannheim, Germany).

\section{Statistical methods}

Reference intervals both from the selected patients and from the healthy reference subjects were calculated as recommended by the International Federation of Clinical Chemistry (26). The number of reference values was large enough to study in detail the effects of sex, age and their interaction on analyte levels by regression analysis. The data were logarithmically transformed to correct for skewness. If statistically significant $(p<0.05)$ effects were found, the data were subgrouped according to sex and/or the effect of age was taken into account by calculating age-specific reference limits by regression analysis. The $95 \%$ age specific prediction intervals of logarithmically transformed values were calculated using the following established formula for prediction of $Y$ values when the original data points and the regression function are known (27):

$$
L\left(Y_{x}\right)=Y_{x} \pm 1.96 \cdot s_{y, x} \cdot \sqrt{\left(1+\frac{1}{n}+\frac{x^{2}}{\Sigma x^{2}}\right)}, \text { where }
$$

$L\left(Y_{x}\right)$ is the lower(-) and upper(+) $95 \%$ predicted limit for $Y$ at a certain age $x, Y_{x}$ is the predicted $Y$ at age $X, s_{y_{0},}$ is the mean standard deviation of the differences between the observed $y$ 's and the predicted Y's, $n$ is the number of observations and $x$ is the difference between the observed age and the mean of all ages of reference subjects. Lower and upper $95 \%$ predicted limits in original scale were obtained after retransformation of the logarithms.

By this method, age-subgrouping was avoided $(28,29)$. The Statistical Analysis System ${ }^{\oplus}$ (SAS Institute, Inc., Cary, NC), REFVAL ${ }^{\circledR}$ (30) and Lotus 1-2-3 (Lotus Development Corp., Cambridge, MA) software packages on a microcomputer were used for the data analysis and graphic presentation. 


\section{Results}

Healthy reference subjects $(n=246)$

Table 1 shows the mean enzyme activities in comparison with other groups. The subgrouping of healthy reference subjects shown in table 2 was based on the following significant $(p<0.05)$ effects of sex and/or age: for creatine kinase, sex; for lactate dehydrogenase, age and the interaction of sex and age; for lactate dehydrogenase isoenzyme 1, age. Although the interaction of age and sex was significant for lactate dehydrogenase, the effect of sex was not significant after considering the age effect. Consequently, gender subgrouping was considered necessary only for creatine kinase. Activities of lactate dehydrogenase and lactate dehydrogenase isoenzyme 1 increased with age. The coefficients of determination $\left(\mathrm{R}^{2}\right)$ of age were $14 \%$ for lactate dehydrogenase and $10 \%$ for lactate dehydrogenase isoenzyme 1 . The age and sex specific reference limits are shown in table 2 .

\section{"Health" related data from selected patients $(\mathrm{n}=538)$}

Of the 2029 hospital patients, 991 patients (49\%) had at least one exclusion diagnosis and 1253 patients (62\%) had at least one change between consecutive enzyme measurements that exceeded the reference change limit. Both exclusion criteria were present in 778 patients (38\%). Twenty five patients were excluded because of macromolecular creatine kinase-BB forms. After all these exclusion steps a total of $538(27 \%)$ of the 2029 patients remained in the reference group. Of the patients 287 were men, aged 25 to 90 (mean 63 years), 251 were women aged 29 to 98 (mean 68 years). The hospital admission enzyme results of these patients were considered as suitable "health"-related reference values.

In the analysis of sex and age effects, we identified the following significant $(p<0.05)$ effects: for creatine kinase, sex and the interaction of sex and age; for creatine kinase-MB, age; for lactate dehydrogenase, age and for lactate dehydrogenase isoenzyme 1, age. Consequently, gender subgrouping was considered necessary for creatine kinase values. After subgroüping, age had a significant effect for creatine kinase values in men but not in women. The creatine kinase values of men declined with age until at old age they were almost similar to those of women (see fig. 1). Creatine kinase=MB, lactate dehydrogenase and lactate dehydrogenase isoenzyme 1
Tab. 1 Mean enzyme activities in different reference groups. For angina and myocardial infarction patients the mean activities repre- sent the individual peak values during follow up. All enzyme activities are given in $U / 1$.

\begin{tabular}{|c|c|c|c|c|c|c|}
\hline Reference group & $\begin{array}{l}\text { Number } \\
\text { of } \\
\text { subjects }\end{array}$ & $\begin{array}{l}\text { Age (years) } \\
\text { mean (SD) }\end{array}$ & $\begin{array}{l}\text { Creatine } \\
\text { kinase } \\
\text { mean (SD) }\end{array}$ & $\begin{array}{l}\text { Creatine } \\
\text { kinase-MB } \\
\text { mean (SD) }\end{array}$ & $\begin{array}{l}\text { Lactate } \\
\text { dehydro- } \\
\text { genase } \\
\text { mean (SD) }\end{array}$ & $\begin{array}{l}\text { Lactate } \\
\text { dehydro- } \\
\text { genase } \\
\text { isoenzyme } 1 \\
\text { mean (SD) }\end{array}$ \\
\hline Healthy reference subjects & 246 & $47(11)$ & $106 \quad(56)$ & $(5.1)$ & $325(64)$ & $76(16)$ \\
\hline "Healthy" patients & 538 & $65(14)$ & $88 \quad(51)$ & (3.8) & $373(121)$ & 79 (21) \\
\hline "Angina(-)" patients & 332 & $67(12)$ & 91 (46) & $(4.1)$ & $376(88)$ & 81 (24) \\
\hline "Angina (+)" patients & 239 & $66(13)$ & $260(343)$ & $19.4(21.9)$ & $493(261)$ & 111 (83) \\
\hline "Myocardial infarction" patients & 471 & $66(12)$ & $1433(1548)$ & $123(110)$ & $1185(852)$ & $457(405)$ \\
\hline
\end{tabular}

Tab. 2 Age- and sex-specific health related reference intervals as produced from healthy subjects and selected "healthy" patients.

\begin{tabular}{|c|c|c|c|c|c|c|}
\hline $\begin{array}{l}\text { Reference group } \\
\text { (number of subjects) }\end{array}$ & $\begin{array}{l}\text { Age group } \\
\text { (years) }\end{array}$ & $\begin{array}{l}\text { Creatine } \\
\text { kinase } \\
\text { men } \\
(\mathrm{U} / \mathrm{l})\end{array}$ & $\begin{array}{l}\text { Creatine } \\
\text { kinase } \\
\text { women } \\
(\mathrm{U} / \mathrm{l})\end{array}$ & $\begin{array}{l}\text { Creatine } \\
\text { kinase-MB } \\
(\mathrm{U} / \mathrm{l})\end{array}$ & $\begin{array}{l}\text { Lactate } \\
\text { dehydrogenase } \\
\text { (U/l) }\end{array}$ & $\begin{array}{l}\text { Lactate } \\
\text { dehydrogenase } \\
\text { isoenzyyme } 1^{\prime} \\
(U / 1)\end{array}$ \\
\hline $\begin{array}{l}\text { Healthy reference subjects } \\
(246)\end{array}$ & $\begin{array}{l}25-34 \\
35-44 \\
45-54 \\
55-64 \\
65-\end{array}$ & $\begin{array}{l}54-285 \\
54-285 \\
54-285 \\
54-285 \\
54-285\end{array}$ & $\begin{array}{l}38-158 \\
38-158 \\
38-158 \\
38-158 \\
38-158\end{array}$ & $\begin{array}{l}5-18 \\
5-18 \\
5-18 \\
5-18 \\
5-18\end{array}$ & $\begin{array}{l}213-397 \\
225-419 \\
238-442 \\
251-468 \\
265-495\end{array}$ & $\begin{array}{l}45-103 \\
48-108 \\
50-115 \\
53-122 \\
56-129\end{array}$ \\
\hline $\begin{array}{l}\text { "Healthy" patients } \\
(538)\end{array}$ & $\begin{array}{l}25-34 \\
35-44 \\
45-54 \\
55-64 \\
65-74 \\
74-\end{array}$ & $\begin{array}{l}40-268 \\
38-250 \\
35-223 \\
33-218 \\
31-204 \\
29-192\end{array}$ & $\begin{array}{l}25-200 \\
25-200 \\
25-200 \\
25-200 \\
25-200 \\
25-200\end{array}$ & $\begin{array}{l}3-16 \\
3-18 \\
3-19 \\
3-20 \\
4-22 \\
4-24\end{array}$ & $\begin{array}{l}196-497 \\
204-516 \\
212-537 \\
221-558 \\
230-580 \\
238-603\end{array}$ & $\begin{array}{l}41-103 \\
44-109 \\
47-116 \\
50-123 \\
53-132 \\
56-140\end{array}$ \\
\hline
\end{tabular}


increased with age (see tab. 1 and fig. 2). Although the age effects were statistically significant, the coefficients of determination $\left(\mathrm{R}^{2}\right)$ of age were quite low: $4.5 \%$ for creatine kinase-MB, $6.0 \%$ for lactate dehydrogenase and $8.7 \%$ for lactate dehydrogenase isoenzyme 1 . Table 2 shows the age and sex specific reference limits.

\section{Patients with angina pectoris $(n=571)$}

A total of 899 of the 2029 patients (44\%) had a discharge diagnosis of angina pectoris, and 571 angina pectoris patient did not have any other diagnoses that would have affected enzyme values. Of these, 332 patients all showed changes in their serial cardiac enzyme results within the reference change limits (angina(-) patients); whereas 239 patients showed at least one change that was higher than the respective reference change limit (angina $(+)$ patients). The means of peak enzyme activities of both groups of angina patients are shown in table 1 together with data from other groups.

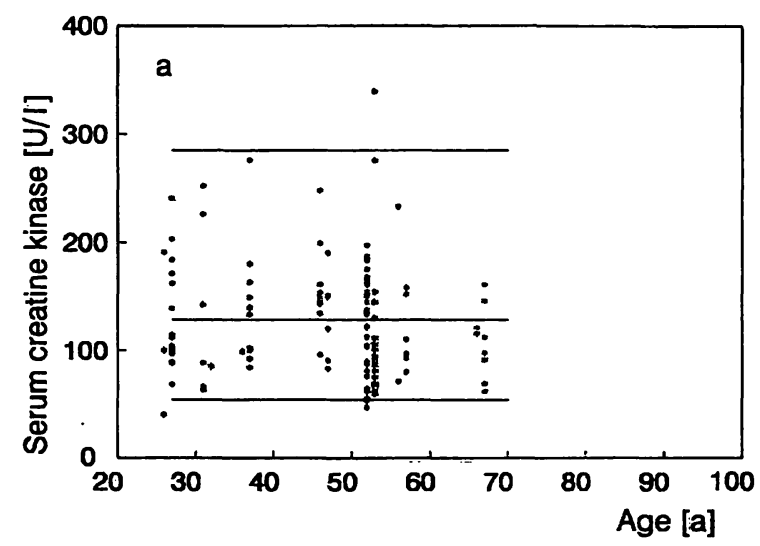

Fig. 1 Plot of creatine kinase activities in men as a function of age in

a) healthy references subjects and in

b) selected "healthy" patients.

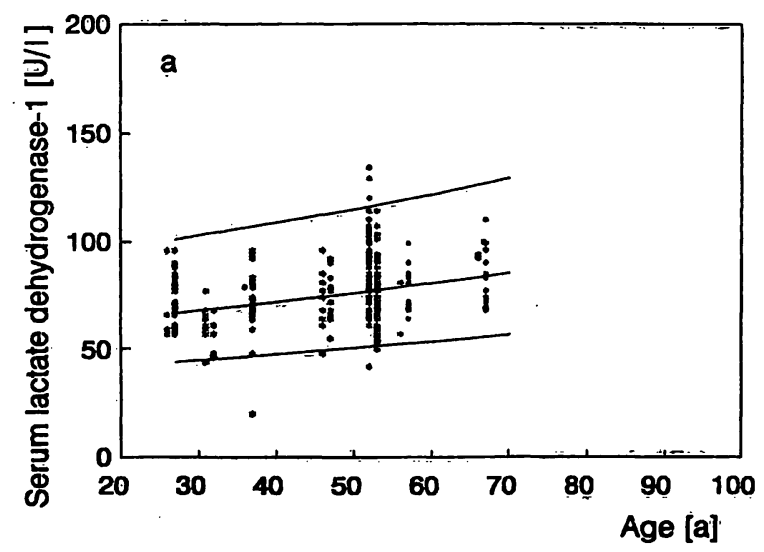

Fig. 2 Plot of lactate dehydrogenase isoenzyme 1 activities as a function of age in

a) healthy reference subjects and in

b) selected "healthy" patients.
Patients with myocardial infarction $(n=471)$

A total of 616 of the 2029 patients (30\%) had a discharge diagnosis of acute myocardial infarction. Almost all $(596,97 \%)$ of the myocardial infarction patients had at least one change outside the reference change limits. The clinical records of the 20 patients who showed no enzyme changes beyond the reference change intervals, and with a discharge diagnosis of myocardial infarction, were reviewed. This review showed that 5 patients had suffered myocardial infarction at least 3 days before admission to hospital and 9 patients at least 2 days after admission to hospital; for 2 patients a typographical error had led to an erroneously registered myocardial infarction diagnosis; for 1 patient the autopsy findings did not support the clinical diagnosis of myocardial infarction; for 1 patient the clinical records were not available. For only 2 patients we could retrospectively confirm that they had obviously suffered clinically confirmed myocardial infarction during the time period from two days

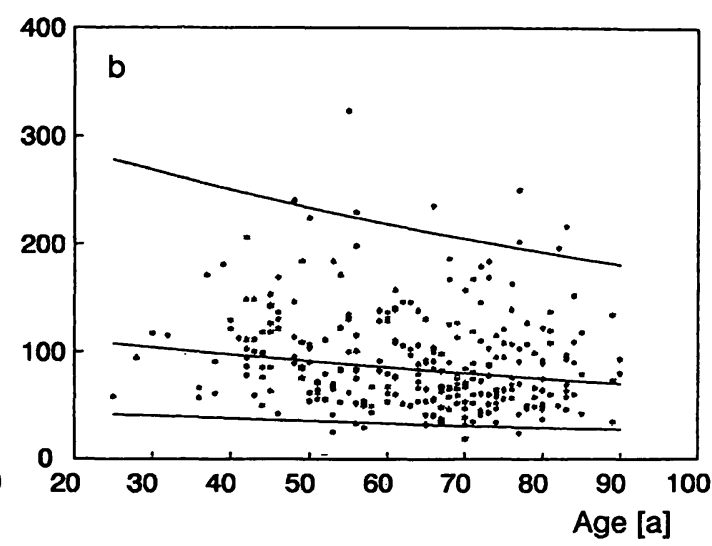

The lines represent the 2.5 th, 50 th and 97.5 th percentile limits as calculated from the logarithmically transformed data. In healthy reference subjects the age dependency is not statistically significant probably due to lack of individuals over 68 years of age.

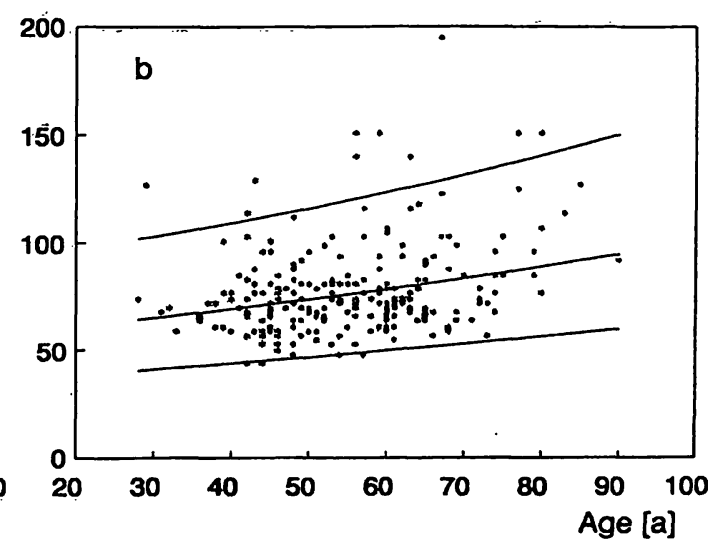

The lines represent the 2.5 th, 50th and 97.5 th percentile limits as calculated from the logarithmically transformed data. Almost identical reference limits were obtained from both groups. 
prior to admission to one day after the admission to hospital, but still did not show enzyme changes exceeding the reference change limits.

Of the 616 patients with myocardial infarction, 145 were excluded because they had also some other diagnoses that could affect creatine kinase or lactate dehydrogenase values. The peak enzyme activity values of the remaining 471 patients were considered as myocardial infarction related reference values. Of the patients 315 were men, aged 20 to 89 , mean 63 years; 156 were women aged 42 to 95 , mean 72 years. The mean peak enzyme activities are shown in table 1 together with results from other groups.

\section{Discussion}

The activities of cardiospecific isoenzymes creatine kinase-MB and lactate dehydrogenase isoenzyme 1 were almost identical in retrospectively selected patients and in the prospective group of healthy reference subjects. Total creatine kinase activities in selected male patients were lower than in healthy reference men. The older mean age of patients at least partly explains this difference. For emergency admission patients it is often impossible to follow procedures for specimen collection similar to those used when specimens are collected from the healthy reference subjects. For example muscle exercise or alcohol consumption may affect total lactate dehydrogenase by increasing the activity of lactate dehydrogenase isoenzyme 4 and lactate dehydrogenase isoenzyme 5 , which are the predominant lactate dehydrogenase isoenzymes in skeletal muscle and liver $(4,5,31)$. These effects would not be seen in lactate dehydrogenase isoenzyme 1 activity. This may also explain our finding that total lactate dehydrogenase activities were higher and showed more variation in selected "healthy" patients than in healthy reference subjects, while at the same time lactate dehydrogenase isoenzyme 1 activities were similar in both groups. Also creatine kinase-MB activities were more similar between the two groups than total creatine kinase activities. Our observations support the superiority of cardiospecific isoenzymes when high signal to noise ratio is desired for the detection of myocardial damage. For less cardiospecific markers it would be especially important to produce reference values from populations with similar preanalytical conditions to those of the patients.

The effect of age on enzyme activities was similar in both retrospective selected patients and in prospective reference subjects, but some of the statistically significant dependencies in the patient group were not significant in the prospective group. The latter group did not include subjects over 67 years of age, which probably explains the observed differences in statistical significances of age effects.

Lactate dehydrogenase and lactate dehydrogenase isoenzyme 1 increased significantly with age in both groups. The increase with age in lactate dehydrogenase activities has also been observed in previous studies (31). Creatine kinase in women did not show statistically significant age-dependency in either of the groups, although increased creatine kinase activities in postmenopausal women have been reported previously (31). In the selected patients group, creatine kinase in men decreased quite markedly with age, while creatine kinase-MB increased with age in both sexes. The decrease with age in total creatine kinase activities in men has been reported previously (31), but to our knowledge, age dependency has not been previously described for creatine kinase-MB or lactate dehydrogenase isoenzyme 1 .

The age distribution of our prospective healthy reference group was not completely satisfactory, as almost half of all the clinical results for interpretation originated from cardiac patients older than 68 years. The reason for the unsatisfactory age distribution in this study, as in many other reference value studies, was simply that samples from healthy aged individuals are not easily available. Definition of health is difficult in old age groups. In the oldest age groups, completely healthy individuals may in fact just form a small minority. However, the observed age effects in this study suggest that subjects older than 67 years should also be included in reference value collections for cardiac enzymes. The method of obtaining reference values from patient data gives a solution to this problem.

In the retrospective approach, the production of reference values resembled the process by which clinicians gain their practical knowledge of clinical significance of laboratory results. A potential source of inaccuracy in this approach is circular reasoning. Results of the considered laboratory tests should not be used as diagnostic criteria in the selection of reference subjects. We attempted to avoid circular reasoning by using information from two sources: the clinical discharge diagnoses database, and the laboratory database, including data of changes between consecutive enzyme measurements. If either of the exclusion criteria applied, the patient was not accepted as a healthy reference subject. In spite of the strict exclusion criteria, the number of remaining reference subjects was high enough to facilitate the calculation of age-specific reference limits. The age distribution of selected "healthy" patients was satisfactory. It corresponded to that of all admitted patients.

In about $60 \%$ of emergency admission angina patients, all enzyme changes were within respective health re- 
lated reference change intervals (angina(-) patients), while about $40 \%$ of angina patients had at least one change outside the limits (angina(+) patients). This observation and the ratio 3 to 2 is in line with previous reports $(14,22)$. Patients with unstable angina and minor myocardial damage have been found to have an unfavourable short-term prognosis (32). The clinical need to diagnose such patients stresses not only the importance of precise methodology for cardiac markers but also the importance of accurate health related reference values and reference change values.

Retrospective selection of myocardial infarction patients was based solely on the discharge diagnoses. Information of the stage of illness or given therapy was not available in the database. For example, a considerable proportion of the patients had received thrombolytic therapy, but no information of this nor any other medication was available in the discharge database. For these reasons we did not consider the myocardial infarction related values clinically useful enough to justify the calculation of reference limits for this diagnostic group.

\section{References}

1. Solberg, H. E. \& Gräsbeck, R. (1989) Reference values. Adv. Clin. Chem. 27, 2-79.

2. Statland, B. E., Winkel, P. \& Bokelund, H. (1973) Factors contributing to intra-individual variation of serum constituents: 2 . Effects of exercise and diet on viariation of serum constituents in health subjects. Clin. Chem. 19, 1380-1383.

3. Nicholson, G. A., Morgan, G., Meerkin, M., Strauss, E. \& McLeod, J. G. (1985) The creatine kinase reference interval: An assessment of intra- and inter-individual variation. J. Neurol. Sci. 71, 225-231.

4. Leppänen, E. A. \& Gräsbeck, R. (1987) Experimental basis of standardized specimen collection: The effect of moderate ethanol consumption on some serum components (K, Na, ASAT, ALAT, CK, LD, total protein). Scand. J. Clin. Lab. Invest. 47, 337-343.

5. Leppänen, E. A. (1989) Expérimental basis of standardized specimen collection: The effect of short moderate exercise on serum K, Ka, ASAT, ALAT, CK and LD. Scand. J. Clin. Lab. Invest. 49, 287-292.

6. Marin, M. M. \& Teichman, S. L. (1992) Use of rapid serial sampling of creatine kinase $\mathrm{MB}$ for very early detection of myocardial infarction in patients with acute chest pain. Am. Heart J. 123, 354-361.

7. Hamfelt, A., Möller, B. H. \& Söderhjelm, L. (1990) Use of biochemical tests for myocardial infarction in the country of Västernorrland, a clinical chemistry routine for the diagnosis of myocardial infarction. Scand. J. Clin. Lab. Invest. 200, 20-25.

8. Gayed, N. M. \& Kern, D. E. (1990) A formula for estimating pretest probability: evaluation and clinical application. J. Gen. Intern. Med. 5, 292-297.

9. Bernstein, L. H., Good, I. J., Holtzman, G. I., Deaton, M. L. \& Babb, J. (1989) Diagnosis of acute myocardial infarction from two measurements of creatine kinase isoenzyme $\mathrm{MB}$ with use of nonparametric probability estimation. Clin. Chem. 35, 444-447.

10. Heliövaara, M., Reunanen, A., Aromaa, A., Knekt, P., Aho, K. \& Suhonen, O. (1984) Validity of hospital discharge data in
Health related reference values were produced from patient databases relatively quickly and at low cost. Unfortunately, the missing data of medication and stage of illness limited the use of databases in the production of illness related data. Such data would be crucial for the estimation of optimal clinical decision limits. In the production of health related data, the combination of several selection criteria is possible, which should make the derived values reliable and clinically useful. Large sets of patient values facilitate the calculation of age and sex specific reference limits. The effects of variable preanalytical conditions, like those related to emergency admission, are better accounted for by using patient data as the source of reference values.

\section{Acknowledgement}

This work was supported by the Research and Science Foundation of Farmos, Turku, Finland. The authors wish to thank Ms. Hanna Finneman, M.Sc., and other staff at the Computer Department of the University Central Hospital of Turku for co-operation in the collection of the data necessary for this study. a prospective epidemiological study on stroke and myocardial infarction. Acta Med. Scand. 216, 309-315.

11. Lloyd, S. S. \& Rissing, J. P. (1985) Physician and coding errors in patient records. J. Am. Med. Ass. 254, 1330-1336.

12. Safran, C. (1991) Using routinely collected data for clinical research. Stat. Med. 10, 559-564.

13. Mähönen, M. (1993) The reliability of hospital discharge data as a tool for epidemiologic research on ischemic heart disease. Comparison of the hospital discharge register and the FINMONICA AMI register. Thesis, University of Helsinki, Helsinki, Finland.

14. Markenvard, J., Dellborg, M., Jagenburg, R. \& Swedberg, K. (1992) The predictive value of CKMB mass concentration in unstable angina pectoris: Preliminary report. J. Intern. Med. $231,433-436$.

15. Hamm, C. W., Ravkilde, J., Gerhardt, W., Jorgensen, P., Peheim, E., Ljungdahl, L., Goldmann, B. \& Katus, H. A. (1992) The prognostic value of serum troponin- $\mathrm{T}$ in unstable angina. N. Engl. J. Med. 327, 146-150.

16. Gerhardt, W., Katus, H., Ravkilde, J., Hamm, C., Jorgensen, P. J., Peheim, E., Ljungdahl, L. \& Löfdahl, P. (1991) S-Troponin $T$ in suspected ischemic myocardial injury compared with mass and catalytic concentrations of S-creatine kinase isoenzyme MB. Clin. Chem. 37, 1405-1411.

17. Apple, F. S. (1992) Acute myocardial infarction and coronary reperfusion - Serum cardiac markers for the 1990s. Am. J. Clin. Pathol. 97, 217-226.

18. Kairisto, V., Virtanen, A., Uusipaikka, E., Voipio-Pulkki, L. M., Näntö, V., Peltola, O. \& Irjala, K. (1993) Method for determining reference changes from patients' serial data: Example of cardiac enzymes. Clin. Chem. 39, 2298-2304.

19. Friedman, R. B. \& Young, D. S. (1989) Effects of Discase on Clinical Laboratory Tests, 2nd ed., AACC Press, Washington.

20. Kouri, T., Kairisto, V., Nurmi, A., Forsström, J., Uusipaikka, E., Juva, K., Rajamäki, A., Koivula, T. \& Näntö, V. (1990) Reference intervals established from data of diagnosis-selected hospitalized patients. Scand J. Clin. Lab. Invest. 50 (Suppl. 202), 220. 
21. World Health Organization MONICA-project (1988) Monitoring trends and determinants in cardiovascular disease: A major international collaboration. J. Clin. Epidemiol. 41, 104-114.

22. Boetker, H. E., Ravkilde, J., Sogaard, P., Jorgensen, P. J., Horder, M. \& Thygsen, K. (1991) Gradation of unstable angina based on a sensitive immunoassay for serum creatine kinase MB. Br. Heart J. 65, 72-76.

23. World Health Organisation (1971) Report of the fifth working group on the establishment of ischaemic heart disease registers, WHO Regional Office for Europe, Copenhagen.

24. Hoerder, M., Magid, E., Pitkänen, E., Härkönen, M., Strömmer, J. H., Theodorsen, L., Gerhardt, W. \& Waldenström, J. (1979) Recommended method for the determination of creatine kinase in blood modified by the inclusion of EDTA. Scand. J. Clin. Lab. Invest. 39, 1-5.

25. Scandinavian Society for Clinical Chemistry and Clinical Physiology (1974) Recommended methods for the determination of four enzymes in blood. Scand. J. Clin. Lab. Invest. 33, 291-306.

26. International Federation of Clinical Chemistry (1987) Approved recommendation (1987) on the theory of reference values. Part 5. Statistical treatment of collected reference values. Determination of reference limits. J. Clin. Chem. Clin. Biochem. 25, 645-656.
27. Snedecor, G. W. \& Cochran, W. G. (1982) Statistical Methods, 7th ed., The Iowa State University Press, Ames, Iowa (p. 166).

28. Vicente, C., Porto, G. \& de Sousa, M. (1990) Method for establishing serum ferritin reference values depending on sex and age. J. Lab. Clin. Med. 116, 779-784.

29. Irjala, K., Koskinen, P., Icen, A. \& Paloșuo, T. (1990) Reference intervals for immunoglobulins IgA, IgG and IgM in serum in adults and in children aged 6 months to 14 years. Scand. J. Clin. Lab. Invest. 50, 573-577.

30. Solberg, H. E. (1983) "REFVAL", Technical Report, Department of Clinical Chemistry, Rikshospitalet, Oslo, Norway.

31. Burtis, C. A. \& Ashwood, E. R. (1994) Tietz Textbook of Clinical Chemistry, 2nd ed., W. B. Saunders Company, Philadelphia.

32. Gerhardt, W. \& Ljungdahl, L. (1993) Rational diagnostic strategy in diagnosis of ischemic myocardial injury. S-troponin T and $\mathrm{S}-\mathrm{CK} \mathrm{MB}$ (mass) time series using individual baseline values. Scand. J. Clin. Lab. Invest. 53, 47-59.

Veli Kairisto, MD

Central Laboratory, Dept. 931

University Hospital of Turku

FIN-20520 Turku

Finland 